\title{
Anucleates, squames, squamous, squamoid and transformations
}

Keywords: heteromorphy, symptomatology, clinical, dysplasia, squamous

Abbreviations: HRA, high resolution anoscopy; LGSIL, low grade squamous intraepithelial lesion; HPV, human papilloma virus; HSIL, high grade squamous intraepithelial lesion; ASIL, anal squamous intraepithelial lesion; AIDS, auto immune deficiency syndrome; HIV, human immune deficiency virus; AGC, atypical glandular cells

\section{Introduction}

Low grade squamous intraepithelial lesion (LSIL/LGSIL) cell augur conceivable cervical dysplasia. LSIL is bland dysplasia (CIN1), besides inclined to be caused by Human Papilloma Virus (HPV) infection and determined by a Papanicolaou smear. Cervical Intraepithelial Neoplasia (CIN 1) is the most conventional and benevolent form of cervical conversions and alterations and usually brings to pass inevitably within two years. So LSIL can be governed with the interim approach. But there is $12 \%-16 \%$ incidence of amelioration to a deeper dysplasia, which compels an offensive followup by colonoscopy and biopsy .Obligatory treatment modalities, which necessitates elimination of the afflicted tissue. Include cryosurgery, cone biopsy, laser ablation and LEEP (Loop Electrosurgical Excision Procedure). High Grade Squamous Intraepithelial Lesion (HSIL) bespeak of moderate to serious cervical intraepithelial neoplasia or carcinoma in situ (CIN $2, \mathrm{CIN} 2 / 3$ or CIN 3$)$ and is usually interpreted by a Papanicolaou essay. In certain instances, it can advance to invasive cervical carcinoma if not pursued appropriately. Only $2 \%$ of the cases have authentic invasive carcinoma at debut, and 20\% would march to invasive cervical cancer without treatment. So to combat the breakthrough, HSIL is hereupon supplanted by colposcopy and biopsy (via endocervical curettage, punch biopsy or conization/cone
Volume 6 Issue | - 2018

\author{
Anubha Bajaj \\ University Panjab University, India
}

\begin{abstract}
Correspondence: Anubha Bajaj, Consultant Pathologist, University Panjab University, Chandigarh, India, Tel 00-91II25II7399,009|98|1693956, Email anubha.bajaj@gmail.com; anubha.bajaj@yahoo.com
\end{abstract} Received: December 09, 2017 | Published: February 15,
2018

biopsy) to amputate the dysplastic tissue. The tissue is directed for histopathological corroboration to assign a histological classification of CIN 2, CIN $2 / 3$ or CIN 3. HSIL treatment denotes deleting or destruction of the altered cells by modalities in accord with those for LSIL which are cryotherapy, cautery, laser ablation or LEEP any of these procedures are $85 \%$ effective in curing the problem (Figure 1).

High risk human papilloma virus (HPV) types 16,18,31,33,45,52,58 can defile cervical cells and generate carcinomatous changes. They also stimulate anal cancer, penile cancer, vaginal cancer, vulval cancer, oropharyngeal cancer (middle of the throat, tonsils and back of the tongue) Low risk HPV infections, type 6\&11 cause genital warts, the potentiality of which do not lead to cancer. HPV inquiry can bring to light infection and the genre of virus that account for cancer. Papanicolaou test is performed to pinpoint the cervical cells that experience malignant transformation and their pre-existing neoplastic counterparts. Cotesting is when both Papanicolaou testing and HPV testing is done concomitantly, for augmenting diagnostic accuracy.

Figure I Compare the LSIL \& HSIL treatment.

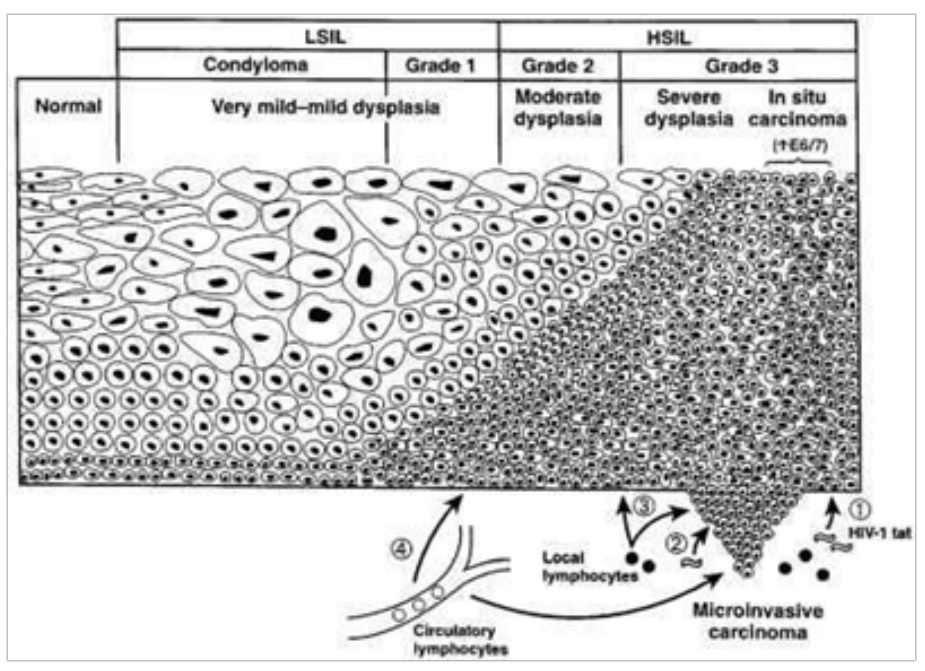




\section{Anal lesions}

Also exist as LSIL and HSIL. A lesion in the expanse of anomalous tissue will promote to observable carcinoma, irrespective of the grade. HSIL is also designated as Anal Dysplasia. Squamous Intraepithelial lesion is related to a range of heteromorphy tissue over and above the covering skin. Extensive dysplasia extending below the pectinate line is the cogitation of anal cancer. Only one per thousand cases are seen to convert from HSIL to frank, invasive malignancy. Lesions are customarily identified by clinicians resorting to High Resolution Anoscopy (HRA). A tiny tissue fragment is extracted for surgical assessment. The anal neoplasias are generally painless and are detected on symptomatology and clinical examination including HRA. Occasionally the internal lesions bleed and external lesions scratch. HSIL is prominently targeted to prevent their progression to an observable tumour. The frequency of anal squamous cell carcinoma in homosexual or bisexual men surpasses that of the heterosexual men ${ }^{1-5}$ and is greater than that of cervical cancer in females. ${ }^{6}$ Appraisal of occurrence of anal squamous cell carcinoma is augmented in homosexual or bisexual males affected with HIV. ${ }^{7,8}$ Both cervical and anal epithelium may comprise of atypical squamous cells of undetermined significance or Low grade squamous intraepithelial lesion (LSIL) or High grade squamous intraepithelial lesion (HSIL). ${ }^{9,10}$ Attributed to the affinity between cervical and anal squamous intraepithelial lesion (ASIL), anal squamous cell carcinoma and displaying an enduring affiliation with anogenital Human Papilloma Virus (HPV) infection, high grade anal squamous intraepithelial lesion (HSIL) probably symbolizes as a precursor to anal squamous cell carcinoma. Homosexual and bisexual males with HPV have an escalated possibility for the continual human papilloma virus (HPV) infection and HPV related anal squamous epithelial lesion (ASIL) with the predominance of anal squamous cell carcinoma ( SCC) percentage deviating from $20 \%$ to $45 \%{ }^{8,11-17}$ Current evaluation of the characteristics of anal disease demonstrate that anal squamous intraepithelial lesions (ASIL) can ameliorate to a higher grade lesion in a brief duration and that the reversion of high grade ASIL is infrequent. ${ }^{15,16}$ Contemporary descriptions of anal squamous cell carcinoma ${ }^{7,8}$ amid males diagnosed with Auto Immune Deficiency Syndrome (AIDS) convey that Human Immune deficiency Virus (HIV) positive homosexual and bisexual males are at a substantial risk for elaborating anal squamous cell carcinoma. Besides, in contrast to the innumerable malignancies in HIV positive men, anal squamous cell carcinoma could be intercepted. Cervical cell carcinoma screening programme can be utilized to engender a prototypical anal cytology screening essay to impede the progress of anal cancer in these high risk men: ${ }^{18-20}$

i. Contingencies for Anal Squamous Cell Carcinoma ${ }^{12,21,22}$

ii. History of lower genital tract neoplasia (e.g. HSIL, carcinoma)

iii. HIV seropositivity

iv. Low $\mathrm{C} 4+$ counts

v. Immunosuppression (solid organ allograft, cyclosporine therapy)

vi. Heavy cigarette smoking

vii. Anoreceptive Intercourse

viii. Infection with multiple HIV genotypes ix. Persistent high risk HPV genotype infection

\section{x. Radiation}

Females with anal HPV infection are at a greater hazard for HPV co-infection of the uterine cervix. Aforesaid lesions should also be examined when anal lesions are recognized.

\section{Audit and appraisals}

i. First Papanicolaou testing to commence at age 21 years.

ii. Every three years from age 21-29years. HPV testing is not advocated as most infections are self-defining and conclude in a short period. With an anomalous Papanicolaou smear, follow through with HPV is also counseled.

iii. For women between age 30-65years, coexistent Papanicolaou smear and HPV confirmation every 5years is advisable or only a Papanicolaou smear every 3years.

iv. For patients older than 65years, with conventional and customary earlier screening, no further estimation is needed. For unusual antecedents and determinations, and infrequent regular screening, instructions from the referring $\mathrm{GP} /$ healthcare provider is desirable.

\section{Exceptions to the ground rules}

The periodicity of the perusals ought to be added to in the ensuing scenarios: Patients are:

i. HIV positive

ii. Have a weakened immune response

iii. Were exposed before birth to diethylstilboestrol(DES), which were once prescribed to pregnant women

iv. Not long past atypical Papanicolaou/tissue evaluation

v. Earlier circumstance of cervical carcinoma. Appraisal is not entailed for women who have had hysterectomy for reasons not related to undisguised cervical cancer/dysplasia. For contradictory instances, an appropriate consultation is needed..$^{23,24}$

\section{Corollaries of the papanicolaou}

ASC-US (Atypical Squamous Cells of Undetermined Significance) is the habitual bizarre papanicolaou test finding A few atypical cells are deciphered, however it is unclear if the changes are due to HPV infection. Associated causes are irritation, bacterial and fungal infections. Polyps, benign growths and cysts, hormonal changes in pregnancy and menopause. The cellular morphology is deviant but unrelated to neoplastic transformation.HPV elimination is essential as is recapitulating the Papanicolaou at 12 months.

(AGC) Atypical Glandular Cells announcing the existence of atypical looking glandular cells envisaging the compulsion of over and above checking in the form of colposcopy and biopsy:

i. LSIL (Low Grade Squamous Intra Epithelial Lesion) Changes subsequent to infection by HPV, which spontaneously regress. Grave forms entail supplementary evaluation.

ii. ASC-H (Atypical Squamous Cells -cannot exclude HSIL) 
Appended atypical squamous cells which are of a serious grade, and may be similar to HSIL. Extended evaluation anticipated.

iii. HSIL (High Grade Squamous Intra Epithelial Lesion) with moderate to severe dysplasia. Created by an HPV infection and may advance to a full blown malignancy, requiring adjuvant delineation.

iv. AIS (Adenocarcinoma in situ) means a dominant lesion of divergent growth is located in the cervical glandular tissue. May build up to cervical adenocarcinoma with anticipated extingencies.

\section{Acknowledgements}

None.

\section{Conflict of interest}

The author declares no conflict of interest.

\section{References}

1. Wexner S. The demographics of anal precursors are changing: Identification of a high risk population. Dis Colon Rectum. 1987;30:942-946.

2. Holly EA, Whittemore AS, Aston DA, et al. Anal cancer incidence: genital warts, anal fissure or fistula, hemorrhoids, and smoking. J Natl Cancer Inst 1989;81(22):1726-1731.

3. Daling JR, Weiss NS, Hislop TG, et al. Sexual practices, sexually transmitted diseases, and the incidence of anal cancer. $N$ Engl J Med. 1987;317(16):973-977.

4. Melbye M, Rabkin C, Frisch M, et al. Changing patterns of anal cancer incidence in the United States, 1940-1989. Am J Epidemiol. 1994;139(8):772-780.

5. Koblin BA, Hessol NA, Zauber AG, et al. Increased incidence of cancer among homosexual men, New York city and San Francisco, 1978-1990. Am J Epidemiol. 1996;144(10):916-923.

6. Qualters JR, Lee NC, Smith RA, et al. Breast and cervical cancer surveillance, United States, 1973-1987. MMWR CDC Surveill Summ. 1992;41(2):1-7.

7. Melbye M, Coté TR, Kessler L, et al. High incidence of anal cancer among AIDS patients. The AIDS/Cancer working group. Lancet. 1994;343(8898):636-639.

8. Goedert JJ, Coté TR, Virgo P, et al. Spectrum of AIDS-associated malignant disorders. Lancet. 1998;351(9119):1833-1839.

9. Palefsky J. Human papillomavirus-related disease in people with HIV. Curr Opin HIV AIDS. 2009;4(1):52-56.
10. Goldie SJ, Kuntz KM, Weinstein MC, et al. The clinical effectiveness and cost-effectiveness of screening for anal Squamous intraepithelial lesions in homosexual and bisexual HIV-positive men. JAMA. 1999;281(19):18221829.

11. Palefsky JM, Holly EA, Gonzales J, et al. Natural history of anal cytologic abnormalities and papillomavirus infection among homosexual men with group IV HIV disease. J Acquir Immune Defic Syndr. 1992;5(12):12581265.

12. Kiviat NB, Critchlow CW, Holmes KK, et al. Association of anal dysplasia and human papillomavirus with immunosuppression and HIV infection among homosexual men. AIDS. 1993;7(1):43-49.

13. Longacre TA, Kong CS, Welton ML. Diagnostic problems in anal pathology. Adv Anat Pathol. 2008;15(5):263-278.

14. Encyclopaedia for Bethesda system of classifying squamous lesions.

15. Palefsky JM, Holly EA, Ralston ML, et al. High incidence of anal highgrade squamous intra-epithelial lesions among HIV-positive and HIVnegative homosexual and bisexual men. AIDS. 1998;12(5):495-503.

16. Palefsky JM, Holly EA, Hogeboom CJ, et al. Virologic, immunologic and clinical parameters in the incidence and progression of anal squamous intraepithelial lesions in HIV-positive and HIV-negative homosexual men. J Acquir Immune Defic Syndr Hum Retrovirol. 1998;17(4):314-319.

17. Anal cancer information from University of California San Francisco Anal Dysplasia Clinic, USA.

18. Palefsk JM. Anal HPV infection and anal cancer in HIV positive individuals: an emerging problem. AIDS. 1994;8:283-295.

19. Northfelt DW, Swift PS, Palefsky JM. Anal neoplasia. Pathogenesis, diagnosis, and management. Hematol Oncol Clin North Am. 1996;10(5):1177-1187.

20. Palefsky JM, Holly EA, Hogeboom CJ, et al. Anal cytology as a screening tool for anal squamous intraepithelial lesions. J Acquir Immune Defic Syndr Hum Retrovirol. 1997;14(5):415-422.

21. Palefsky JM, Shiboski S, Moss A. Risk factors for anal human papillomavirus infection and anal cytologic abnormalities in HIV-positive and HIV-negative homosexual men. J Acquir Immune Defic Syndr. 1994;7(6):599-606.

22. Palefsky JM, Holly EA, Ralston ML, et al. Prevalence and risk factors for human papillomavirus infection of the anal canal in human immunodeficiency virus (HIV)-positive and HIV-negative homosexual men. J Infect Dis. 1998;177(2):361-367.

23. Cancer Cervical. USA: National cancer institute.

24. https://www.78stepshealth.us/barr-virus/natural-history-of-cervical-hpvinfection-and-csil.html 